\title{
An Application Jeevan - Kushalaiah Method to Find Lagrangian Multiplier in Economic Load Dispatch Including Losses and Lossless Transmission Line
}

\author{
Neelam Jeevan Kumar \\ Electric and Electronics Engineering, H.No: 19-6-194, Rangashaipet, Warangal, Andhra Pradesh, India-
} 506005

Abstract: This paper discusses the non iterative method to calculate the Lagrangian Multiplier ( $\lambda$ ). The economic load dispatch (ELD) is the on-line economic load dispatch (ELD) wherein it is required to distribute the load among the generating units. The system such manner as to minimize the total cost of supplying the minute -to- minute requirements of systems. Jeevan - Kushalaiah method or J-K method is a method to calculate maximum number of combination between n-elements starting from minimum order to maximum order. The J-K method modifies iterative flow charts to single line flow charts. This paper deals with NewtonRaphson method.

Index terms: Jeevan - Kushalaiah method, Incremental Fuel Rate, Incremental Transmission Cost

\section{Introduction}

In load flow studies, For a particular load demand the generation at all generator buses are fixed except at the generator bus known as slack bus or reference bus or swing bus. In case of Economic Load Dispatch (ELD) the generations are not fixed but they are allowed to take values again the within certain limits so as to meet a particular load demand with minimum fuel consumption.

The cost of generation will depend upon the system constraint for a particular load demand. This means the cost of the generation is not fixed for a particular load demand but depends upon the operating constrains of the generator. The various constraints in economic load dispatch are

\section{Equality Constrains:}

\begin{tabular}{|c|c|}
\hline 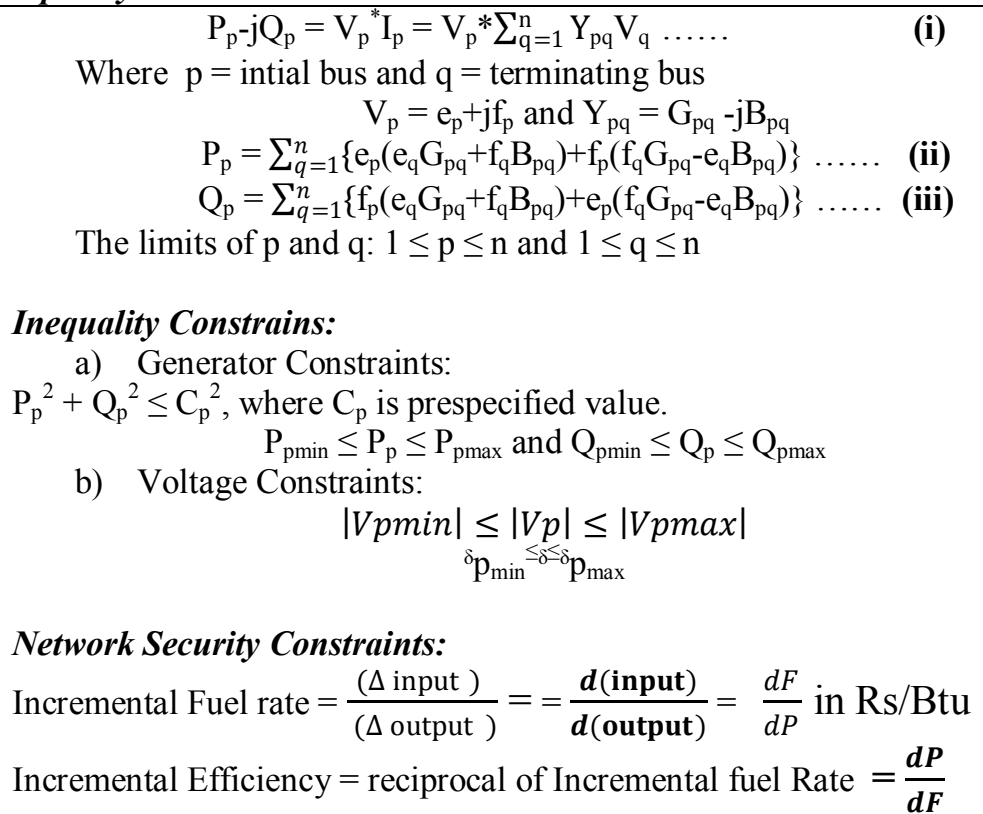 & $\begin{array}{l} \\
\mathrm{P}_{\min } \\
\text { X-axis(Power ouput in } \mathrm{MW} \text { ) }\end{array}$ \\
\hline
\end{tabular}

\section{Jeevan - Kushalaiah Method}

Jeevan - Kushalaiah method is a method to find maximum number of possible combination between $\mathrm{n}$ elements.

Let $n$-elements $a_{1}, a_{2}, a_{3}, a_{4}, \ldots \quad a_{n-1}, a_{n}$

The maximum number of combination between elements are 
$\left\{(1),\left(a_{1}, a_{2}, a_{3}, a_{4}, \ldots a_{n-1}, a_{n}\right),\left(a_{1} a_{2}, a_{1} a_{3}, a_{1} a_{4}, \ldots a_{1} a_{n-1}, a_{1} a_{n} \ldots a_{2} a_{3}, a_{2} a_{4}, \ldots a_{2} a_{n-1}, a_{2} a_{n} \ldots \ldots a_{3} a_{4}, a_{3} a_{5}, \ldots\right.\right.$ $\left.a_{3} a_{n-1}, a_{3} a_{n} \ldots \ldots \ldots \ldots a_{n-1} a_{n}\right),\left(a_{1} a_{2} a_{3}, a_{1} a_{2} a_{4}, \ldots a_{1} a_{2} a_{n-1}, a_{1} a_{2} a_{n} \ldots \ldots \ldots a_{n-2} a_{n-1} a_{n}\right), \ldots \ldots,(\ldots \ldots), \ldots \ldots,\left(a_{1} a_{2} a_{3} \ldots a_{n-}\right.$ $\left.\left.{ }_{1} a_{n}\right)\right\}$

$=\left\{\left(\boldsymbol{\Theta}_{0}\right),\left(\boldsymbol{\Theta}_{1}\right),\left(\boldsymbol{\Theta}_{2}\right), \ldots \ldots .\left(\boldsymbol{\Theta}_{\mathrm{p}-1}\right),\left(\boldsymbol{\Theta}_{\mathrm{p}}\right)\right\}$

(iv)

Here $\Theta_{0}=1, \Theta_{1}=+,-, *$, of all elements

$\left(\Theta_{p}\right)=$ Addition or Subtraction or Multiplication or Division or a square Matrix.

Example - 1:

$\left(\Theta_{\mathrm{p}}\right)=(\mathrm{a}, \mathrm{b})$

- $\quad$ Addition $=\mathrm{a}+\mathrm{b}$

- $\quad$ Subtraction $=\mathrm{a}-\mathrm{b}$

- Multiplication $=a^{*} b$

- $\quad$ Division $=\mathrm{a} / \mathrm{b}$

- $\quad$ Square Matrix $=\left[\begin{array}{cc}a 11 & 12 \\ 21 & b 22\end{array}\right]$ ( and $b$ are diagonal positions only.)

Commonly Multiplication and Addition is performed

total number of combinations of n-elements

$$
\Theta_{p}=(n-(p-1))_{p-1}+
$$

The value of $p \geq 2$

$$
=\Theta_{0}+\Theta_{1}+\sum_{p=2}^{2} \Theta_{\mathrm{p}}
$$

where + is summator like factorial operation instead of multiplication addition is performed.

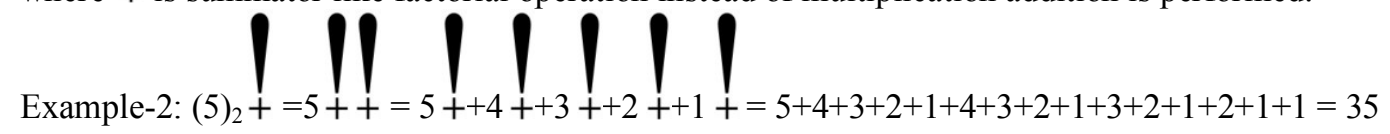

The Load demand $=\mathrm{P}_{\mathrm{D}}$

\section{Calculation of $\lambda$ of ELD without Losses}

The generation of $\mathrm{n}^{\text {th }}$ unit $=\mathrm{P}_{\mathrm{n}}$

Total fuel input to the system $=\mathrm{F}_{\mathrm{T}}$

The Fuel input tot $\mathrm{n}^{\text {th }}$ system $=\mathrm{F}_{\mathrm{n}}$

The system with without losses, $\mathrm{P}_{\mathrm{L}}=0$

$$
\mathrm{P}_{\mathrm{D}}=\sum_{\mathrm{k}=1}^{\mathrm{n}} \mathrm{P}_{\mathrm{k}}
$$

The auxiliary function

$$
\mathrm{F}=\mathrm{F}_{\mathrm{T}}+\lambda\left(\mathrm{P}_{\mathrm{D}}-\sum_{\mathrm{k}=1}^{\mathrm{n}} \mathrm{P}_{\mathrm{k}}\right)
$$

Where $\lambda$ is Lagrangian multiplier

Differentiating $F$ with respect to $P_{n}$ and equating to zero

$$
\frac{\mathrm{dF} 1}{\mathrm{dP1}}=\frac{\mathrm{dF2}}{\mathrm{dP2}}=\frac{\mathrm{dFn}}{\mathrm{dPn}}=\lambda
$$

Where $\frac{\mathrm{dFn}}{\mathrm{dPn}}=$ incremental production cost of nth plant in Rs. /MWhr

For a plant over a limited range

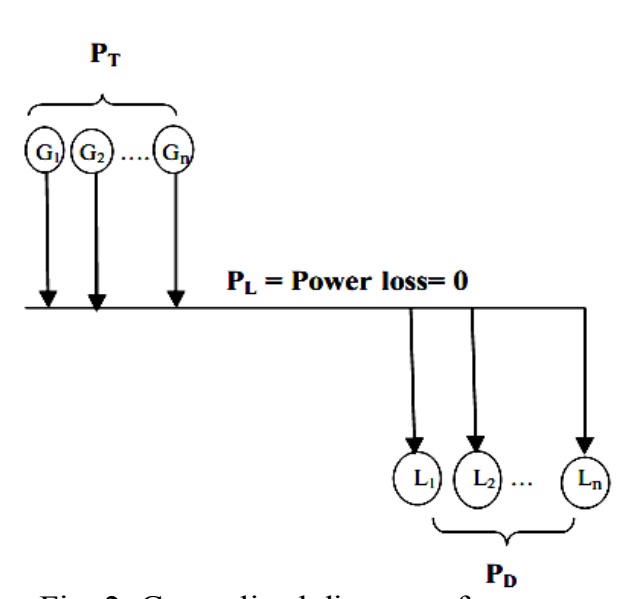

Fig .2: Generalized diagram of a power system without losses.

$$
\frac{d F n}{d P n}=F_{n n} P_{n}+f_{n}=\lambda
$$

Where $\mathrm{F}_{\mathrm{nn}}=$ slope of total incremental production curve and $f_{n}=$ intercept of incremental production cost curve.

From equation number (viii), we have

$$
\begin{gathered}
P_{n}=\left(\lambda_{\text {assum }}-f_{n}\right) / F_{\text {nn }} \\
P_{1}=\left(\lambda_{\text {assum }}-f_{1}\right) / F_{11}, F_{2}=\left(\lambda_{\text {assum }}-f_{2}\right) / F_{22} \ldots \ldots \ldots \\
P_{n-1}=\left(\lambda_{\text {assum }}-f_{n-1}\right) / F_{n-1 n-1}, P_{n}=\left(\lambda_{\text {assum }}-f_{n}\right) / F_{n n}
\end{gathered}
$$

Total power to be generated $\mathrm{P}_{\mathrm{T}}$ is

$\mathrm{P}_{\mathrm{D}}=\mathrm{P}_{1}+\mathrm{P}_{2}+\ldots \ldots+\mathrm{P}_{\mathrm{n}}$ 
$\mathrm{P}_{\mathrm{D}}=\left\{\left(\boldsymbol{\lambda}_{\text {assum }}-\mathrm{f}_{1}\right) / \mathrm{F}_{11}\right\}+\left\{\left(\boldsymbol{\lambda}_{\text {assum }}-\mathrm{f}_{2}\right) / \mathrm{F}_{22}\right\}+\ldots+\left\{\left(\boldsymbol{\lambda}_{\text {assum }}-\mathrm{fn}\right) / \mathrm{F}_{\mathrm{nn}}\right\}$

Rewriting equation-(ix) for direct calculation of $\lambda$

$$
\lambda_{\text {assum }}=\left\{\mathbf{P}_{\mathbf{D}}\left(\sum_{\mathrm{j}=1}^{\mathrm{n}} \mathbf{F}_{\mathrm{jj}}\right)+\sum_{\mathrm{k}=1}^{\mathrm{n}} \mathbf{f}_{\mathrm{k}}\left(\phi_{\mathrm{n}-\mathrm{k}-1}\right)\right\} /\left(\sum_{\mathrm{n}=1}^{\mathrm{n}} \boldsymbol{\phi} \mathbf{n}\right)
$$

Where $\phi \mathrm{n}=$ elements combination in $\Theta_{\mathrm{n}-1}$

\section{Calculation of $\lambda$ of ELD without Losses}

The system with without losses, $\mathrm{P}_{\mathrm{L}}$

$$
\mathbf{P}_{\mathbf{D}}+\mathbf{P}_{\mathbf{L}}=\sum_{\mathbf{k}=\mathbf{1}}^{\mathbf{n}} \mathbf{P}_{\mathbf{k}}
$$

The auxiliary function

$$
\begin{gathered}
\mathbf{F}=\mathbf{F}_{\mathrm{T}}+\lambda\left(\mathbf{P}_{\mathrm{D}}+\mathbf{P}_{\mathrm{L}}-\sum_{\mathrm{k}=\mathbf{1}}^{\mathrm{n}} \mathbf{P}_{\mathrm{k}}\right) \\
\frac{\mathrm{dFn}}{\mathrm{dPn}}+\lambda\left(\frac{\partial \mathrm{PL}}{\partial \mathrm{Pn}}\right)=\lambda \quad \cdots \quad \ldots
\end{gathered}
$$

$\frac{\partial P \mathrm{~L}}{\partial P n}=$ The Incremental Transmission Loss at plant $-\mathrm{n}$

Loss formula approximately

Assumptions

$$
\mathbf{P}_{\mathbf{L}}=\sum_{\mathbf{j}} \mathbf{P}_{\mathbf{j}} \sum_{\mathbf{k}} \mathbf{P}_{\mathbf{k}} \mathbf{B}_{\mathbf{j k}}
$$

- The equivalent load current at any bus remains constant.

- The generator bus voltage magnitude and angles are constant.

- Power factor is constant

$$
\begin{aligned}
& \frac{\partial P L}{\partial P n}=2 \sum_{j} P_{j} B_{j k} \\
& \frac{d F n}{d P n}=F_{n n} P_{n}+f_{n}
\end{aligned}
$$

Substituting equations (xiii)(xiv) in (xii) we get

Rewriting the equation - (xii)

$$
\mathbf{F}_{n n} \mathbf{P}_{n}+\mathbf{f}_{n}+2 \lambda \sum \mathbf{B}_{m n} \mathbf{P}_{m}=\lambda \quad \ldots \ldots
$$

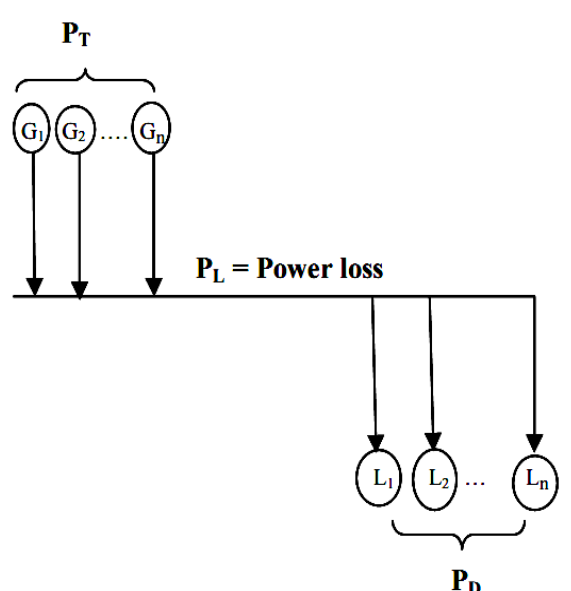

Fig . 3: Generalized diagram of a power system with losses.

From equation - (xiv) in (xvi)

$$
\begin{gathered}
\frac{d F n}{d P n}+\lambda\left(\frac{\partial P L}{\partial P n}\right)=\lambda, \frac{\partial P L}{\partial P n}=L_{n} \\
\frac{d F n}{d P n}+\lambda L_{n}=\lambda \Longrightarrow \frac{d F n}{d P n}=\lambda\left(1-L_{n}\right) \ldots \ldots
\end{gathered}
$$

$$
\begin{gathered}
F_{n n} P_{n}+f_{n}=\lambda\left(1-L_{n}\right) \\
\left(F_{n n} P_{n}+f_{n}\right) /\left(1-L_{n}\right)=\lambda
\end{gathered}
$$

Generation of n-generator $P_{n}=\left\{\lambda\left(1-L_{n}\right)-f_{n}\right\} / F_{n n}$

$\mathrm{P}_{1}=\left\{\lambda\left(1-\mathrm{L}_{1}\right)-\mathrm{f}_{1}\right\} / \mathrm{F}_{11}, \mathrm{P}_{2}=\left\{\lambda\left(1-\mathrm{L}_{2}\right)-\mathrm{f}_{2}\right\} / \mathrm{F}_{22} \ldots \ldots \ldots \ldots \mathrm{P}_{\mathrm{n}}=\left\{\lambda\left(1-\mathrm{L}_{\mathrm{n}}\right)-\mathrm{f}_{\mathrm{n}}\right\} / \mathrm{F}_{\mathrm{nn}}$

$\mathrm{P}_{\mathrm{T}}=\mathrm{P}_{1}+\mathrm{P}_{2}+\mathrm{P}_{\mathrm{n}}=\left\{\lambda\left(1-\mathrm{L}_{1}\right)-\mathrm{f}_{1}\right\} / \mathrm{F}_{11}+\left\{\lambda\left(1-\mathrm{L}_{2}\right)-\mathrm{f}_{2}\right\} / \mathrm{F}_{22}+\ldots \ldots \ldots \ldots+\left\{\lambda\left(1-\mathrm{L}_{\mathrm{n}}\right)-\mathrm{f}_{\mathrm{n}}\right\} / \mathrm{F}_{\mathrm{nn}}$

Rewriting the above equation

$$
\lambda_{\text {assum }}=\left\{P_{D}\left(\sum_{j=1}^{n} F_{j j}\right)+\sum_{k=1}^{n} f_{k}\left(\phi_{n-k-1}\right)\right\} /\left(\sum_{n=1}^{n} \phi n\right)\left(1-L_{n}\right)
$$

\section{Algorithms and Flow Charts}

\section{V.a. Algorithm for ELD without Losses and ELD with losses}

Step-I. Start and Read The Fuel input tot $n^{\text {th }}$ system $\left(F_{n}\right), F_{n n}=$ slope of total incremental production, The Load demand $\left(\mathrm{P}_{\mathrm{D}}\right)$

Step-II. Calculate loss. For ELD without losses $\mathrm{P}_{\mathrm{L}}=0$

Step-III. Calculate $\lambda_{\text {assum }}$, and set bus number, $\mathrm{n}=1$, calculate $\mathrm{P}_{\mathrm{n}}$ check all buses are completed or not, if yes go to next step, if not increment $n=n+1$ repeat step-III

Step-IV Print Generation and calculate cost of generation.

Note: Algorithm for ELD without Losses and ELD with losses changes according to their transmission line losses and operating conditions. In these algorithms are only for normal operation and not affected for atmospheric changes like raining and snow falling on the line. 
Flow chart for ELD without losses

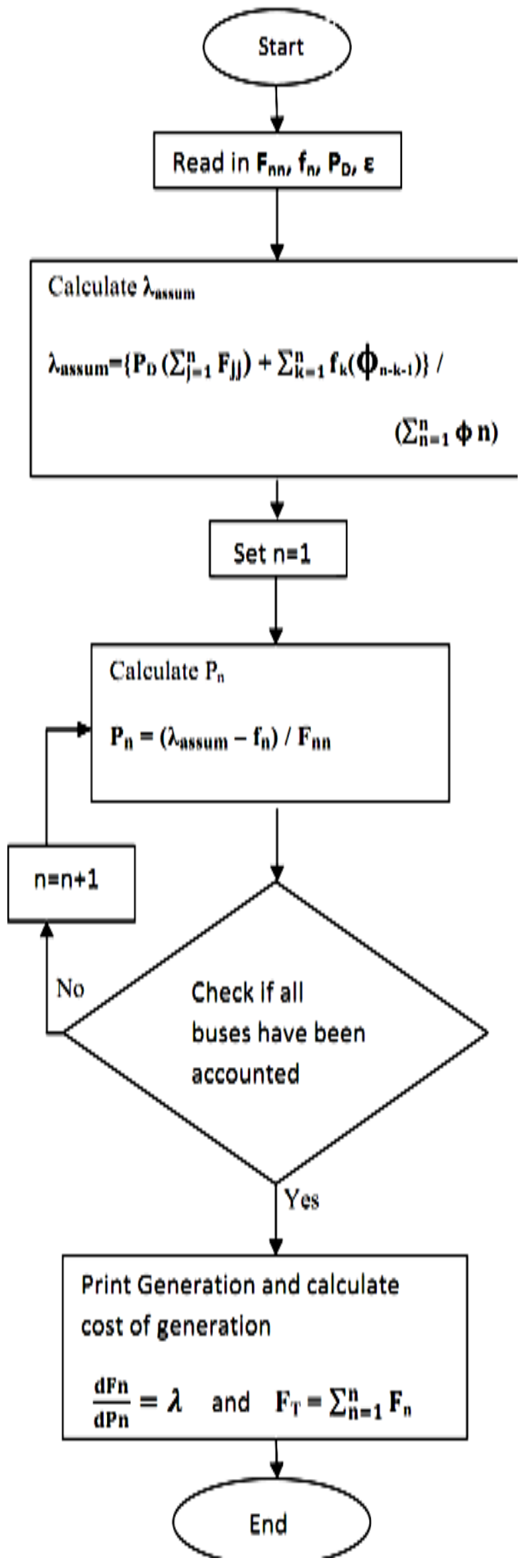

Flow chart for ELD with losses

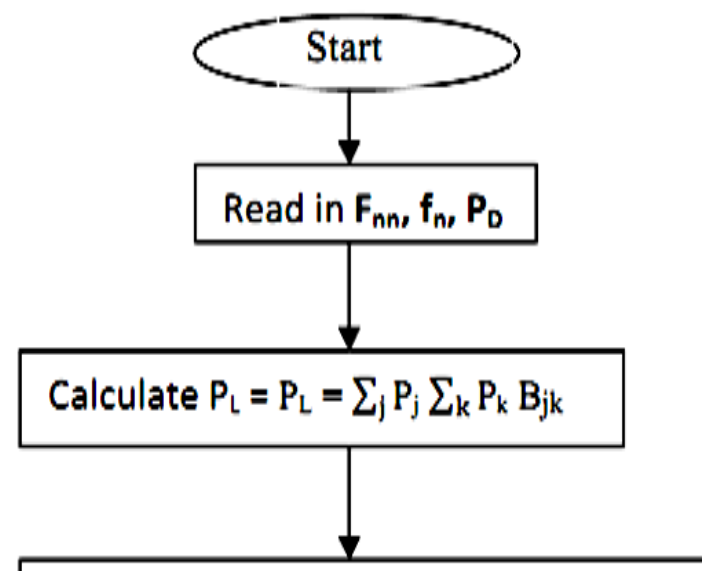

Calculate $\lambda_{\text {assum }}$

$\lambda_{\text {assum }}=\left\{P_{\mathrm{D}}\left(\sum_{j=1}^{\mathrm{n}} \mathrm{F}_{\mathrm{jJ}}\right)+\sum_{\mathrm{k}=1}^{\mathrm{n}} \mathrm{f}_{\mathrm{k}}\left(\phi_{\mathrm{n}-\mathrm{k}-1}\right)\right\} /$

$\left(1-L_{n}\right)\left(\sum_{n=1}^{n} \phi n\right)$
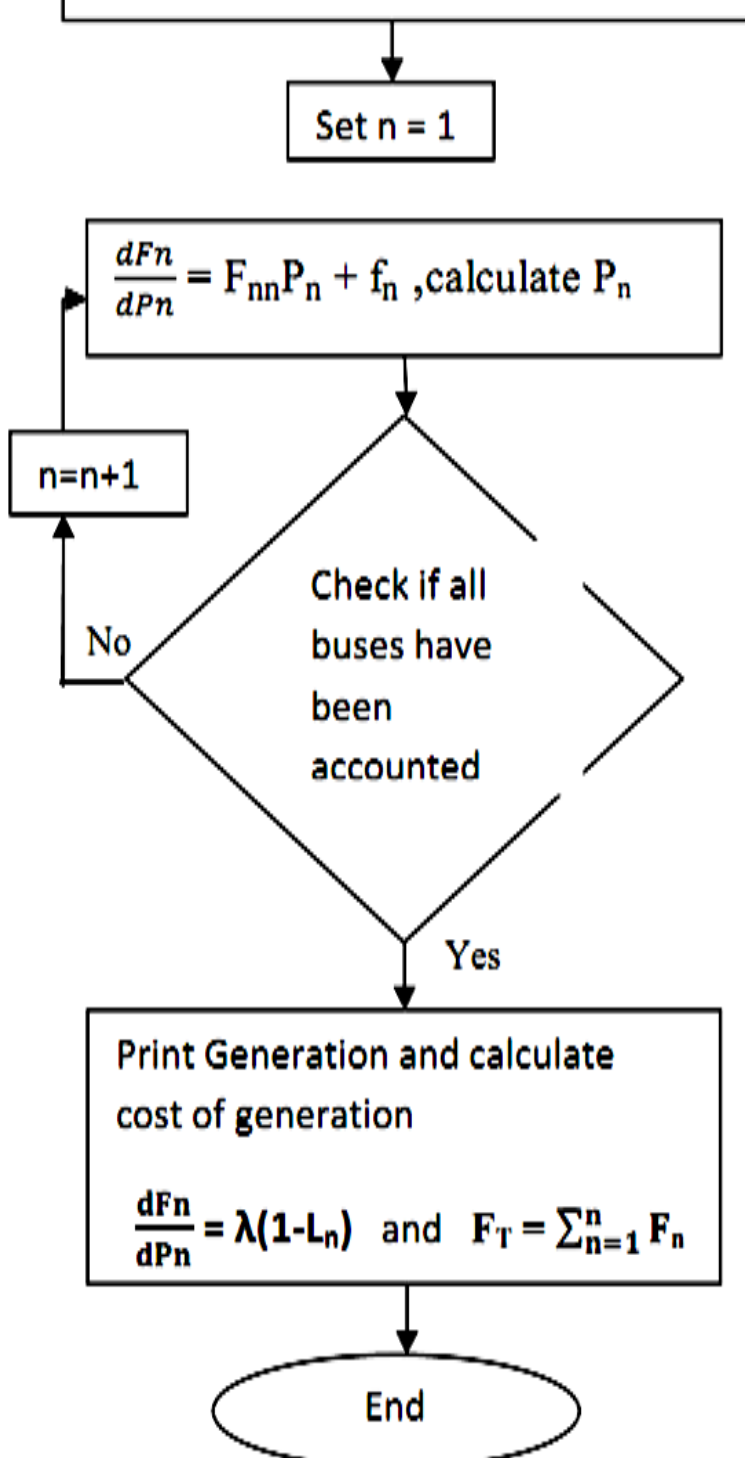
In this method, the Calculated values are within the

\section{Conclusion}

limits of voltage constraints and generator i.e.,

$$
\begin{gathered}
\mid \text { Vpmin }|\leq| \text { Vp }|\leq| \text { Vpmax } \mid \text { and } \\
\mathrm{P}_{\mathrm{pmin}} \leq \mathrm{P}_{\mathrm{p}} \leq \mathrm{P}_{\mathrm{pmax}} \text { and } \mathrm{Q}_{\text {pmin }} \leq \mathrm{Q}_{\mathrm{p}} \leq \mathrm{Q}_{\mathrm{p} \max }
\end{gathered}
$$

And there is iteration process to calculate Lagrangian multiplier $\lambda$,in the flow chart backward path is only for calculating required output at generating stations not to finding out the $\lambda$. This method applied for Thermal and Hydro power stations or connection of Hydro-Thermal Power station and Grid connections.

\section{References}

[1]. Neelam Jeevan Kumar," Jeevan kushalaiah method to find the coefficients of characteristic equation of a matrix and introduction of summetor", 2229-5518, Volume 4, Issue 8,2013

[2]. I.A . Farhat, M.E. El-Hawar y, "Optimization methods applie d for solving the short-term hydrothermal coordination problem", 79 (20 09) 1308-1320, doi:10.1016/j.epsr.20 09.0 4.0 01

[3]. Y.H. Song, Modern Optimization Techniques in Power Systems, Kluwer Aca-demic Publishers, Dordrecht, The Netherlands, 1999

[4]. J.A . Momoh, Electric Power System Applications of Optimization, Marcel Dekker, New York, 2001.

[5]. Basic issues in Lagrangian optimization, in Optimization in Planning and Operation of Electric Power Systems (K. Frauendorfer, H. Glavitsch and R. Bacher, eds.), Physica-Verlag, Heidelberg, 1993, 3-30 (by R. T. Rockafellar)

[6]. R. T. Rockafellar "Lagrange Multipliers and Optimality", 35(2), 183-238. (56 pages), http://dx.doi.org/10.1137/1035044

[7]. book: C.L Wadhwa, ’Electrical power systems”, ISBN 978-81-224-2839-1

\section{Author}

The author is academic researcher, Department Electrical and Electronics Engineering. His research areas are Optimization of Power system and applied mathematics. 